\title{
Working
}

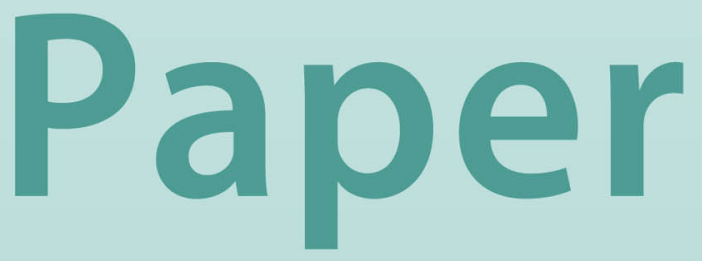




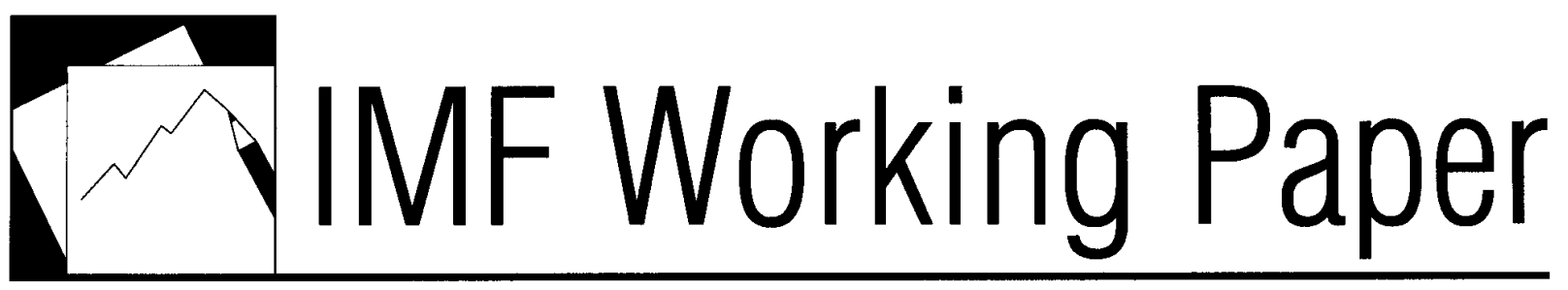

Tracking Short-Term Dynamics of Economic Activity in Low-Income Countries in the Absence of High-Frequency GDP Data Maxwell Opoku-Afari and Shiv Dixit 
This page intentionally left blank 


\title{
IMF
}

African Department

\section{Tracking Short-Term Dynamics of Economic Activity in Low-Income Countries in the Absence of High-Frequency GDP Data}

\author{
Prepared by Maxwell Opoku-Afari and Shiv Dixit ${ }^{1}$
}

Authorized for distribution by Peter Allum

May 2012

\begin{abstract}
This paper uses a set of routinely collected high-frequency data in low-income countries (LICs) to construct an aggregate and a comprehensive index of economic activity which could serve (i) as a measure of the direction of economic activity; and (ii) as a useful input in analyzing contemporaneous real sector performance in LICs in the absence of high-frequency, and often outdated, GDP data. It could also serve as a useful tool for policymakers to gauge short-term dynamics of economic activity and shape appropriate and timely policy responses.
\end{abstract}

JEL Classification Numbers: C02, C18, C63, E01, E32

Keywords: Short-Term Dynamics, Economic Activity, GDP

Author's E-Mail Address: MOpokuAfari@imf.org, dixit.shiv@gmail.com

\section{This Working Paper should not be reported as representing the views of the IMF.}

The views expressed in this Working Paper are those of the author(s) and do not necessarily represent those of the IMF or IMF policy. Working Papers describe research in progress by the author(s) and are published to elicit comments and to further debate.

\footnotetext{
${ }^{1}$ The authors are grateful to colleagues in the African Department of the IMF for providing data and very useful comments.
} 


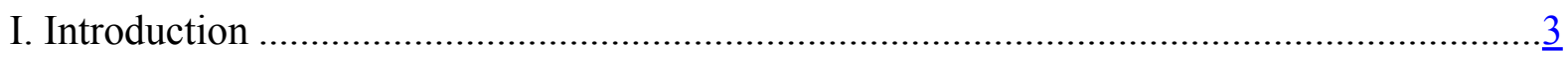

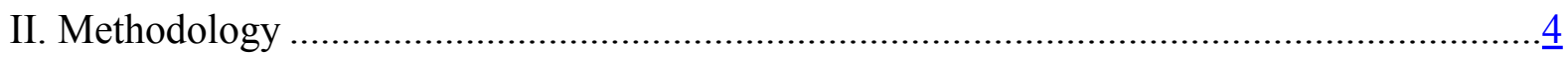

III. Application to Selected Countries ……………............................................................

IV. Interpolating High-Frequency GDP Using the CIEA …………...................................11

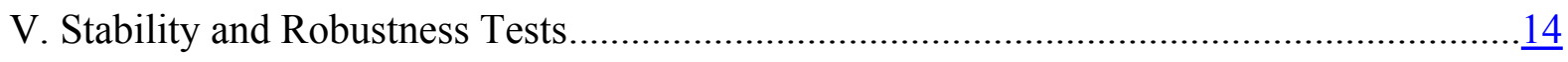

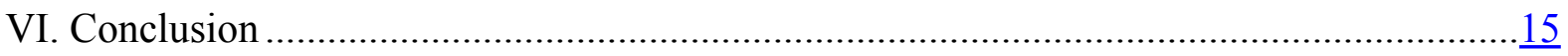

Figures

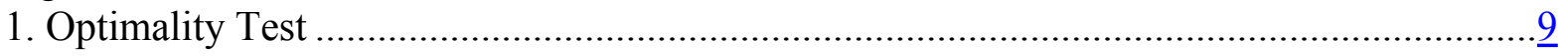

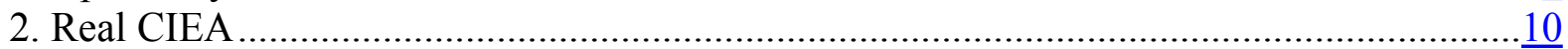

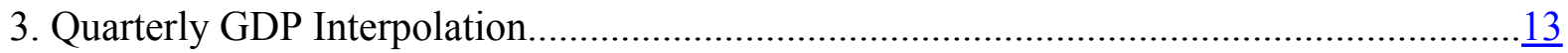

4. Sensitivity Analysis ...........................................................................................

Appendixes

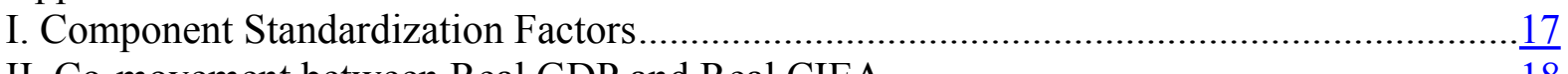

II. Co-movement between Real GDP and Real CIEA .....................................................

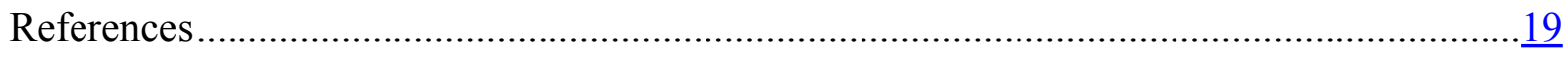




\section{INTRODUCTION}

Understanding turning points of economic activity has come to the fore of macroeconomic management in recent years given poor performances of existing models to effectively predict recessions. Given their extensive contribution to economic fluctuations, forecasting business cycles has proven critical for optimizing economic decision making because it provides a sense of the current state of economic activities and their direction over time. This has been the main motivation of the pioneers of business cycle research. Initial work by Mitchell and Burns (1938) estimated the very first leading indicators of cyclical revival.

Subsequently, the methodology has undergone several very useful changes. Moore and Shiskin (1967), as part of their work at the National Bureau of Economic Research (NBER), published the first composite leading indicators for the U.S. economy-calculated as a weighted average of four well-established and frequently compiled time series variablesusing industrial production, personal income less transfers, employees on non-agricultural payrolls and manufacturing, and trade sales. Their work has been the basis of extensive analysis of coincident and leading indicators in most Organisation for Economic Cooperation and Development (OECD) and other emerging market economies during the last four decades. Key among such works were Layton and Moore (1989) for the U.S. service sector; Zarnowitz (1996) for Mexico; Fabiano and others (2000) for Italy; Lamy and Sabourin (2001) for Canada; and Albu (2008) for Romania.

Indicators of short-term dynamics of economic activity have underpinned macroeconomic decision making in most advanced and emerging market economies. These indicators are viewed as summary statistics for an economy. In most cases, these indicators have been used as a proxy for measuring and understanding aggregate economic activity and have facilitated appropriate and timely policy responses to variations in business cycles. This has, however, not been the case in most low-income countries (LICs) - especially sub-Saharan African (SSA) countries - where high-frequency GDP data are either unavailable or come with a long lag, and hence are irrelevant for contemporaneous policymaking. If LICs are to take advantage of the shifting trends in global trade and finance, then macroeconomic management needs to be enhanced; and understanding and effectively tracking the direction of the economy is critical.

Only a few SSA countries (e.g. South Africa, Ghana, Mozambique) use some form of leading, coincident, or lagging indicators. However, changing dynamics of macroeconomic policymaking in LICs - where managing short-term changes in aggregate demand is increasingly gaining roots in monetary policymaking - would require increasing use of indicators of economic activity to better understand and predict turning points of these economies and inform appropriate policy responses. 
This paper is unique because it augments the existing methodology to suit low-quality and frequently omitted variables common in most developing economies. It also extends the process to test for optimality in selecting components for estimation and tests for stability of the estimated index. Finally, the paper introduces, in the same framework, a combined algorithm for using the Composite Index of Economic Activities (CIEA) to interpolate quarterly GDP that could assist most developing countries in closing this important data gap.

Overall, the paper finds that the estimated CIEA is highly correlated (averaging 0.95) with official quarterly GDP estimates for all countries in our sample. The paper also establishes that the CIEA closely tracks both short- and medium-term turning points in economic activity when benchmarked against official GDP estimates in all the selected countries. In addition, evidence from the paper shows that monetary policy could have been enhanced, in hindsight, with high-frequency assessment of economic activity as central banks try to minimize the output and inflation loss function. Finally, interpolated quarterly GDP using the CIEA for all the selected countries shows a strong correlation with official estimates and is the basis for using the CIEA as an important variable in projecting GDP for LICs where high-frequency GDP estimates are lacking.

The paper is organized as follows: Section I discusses the background of indicators of economic activity and outlines the methodology for estimating the index. Section II discusses comprehensive criteria for selecting components for the index and also the model for estimating the index. Section III applies the model to selected set of SSA countries including optimality tests. Section IV presents techniques for interpolating high-frequency GDP using the estimated CIEA, Section V present stability and robustness tests of the CIEA index, and Section VI concludes the paper.

\section{Methodology}

This paper presents a model - that extends the existing methodology—for estimating shortterm dynamics of economic activities in LICs using high-frequency economic variables that share a common stochastic trend with GDP. With improved economic management and emerging stronger institutions across most LICs in the last two decades, there has been an increase in reporting of high-frequency variables even though quality of data remains an issue. This paper takes advantage of the new data from LICs to apply a modified version of methodology used by The Conference Board of the U.S.A to estimate a coincident indicator of economic activity that would suit the economic characteristics of LICs. The estimated index is benchmarked against official GDP estimates using an augmented version of the work by Friedman (1962) of interpolating quarterly ${ }^{1}$ GDP using a related series. We then

\footnotetext{
${ }^{1}$ This also can be used to interpolate monthly GDP series.
} 
assess the stability and robustness of the CIEA index and outline a procedure of arriving at an optimal set of components for estimating the CIEA by computing marginal contributions (at different timelines) of each component in the sample. This methodology for estimating the CIEA index is applied to a selected number of SSA countries - Rwanda, Kenya, Botswana, and Tanzania. ${ }^{2}$ The estimated CIEA index is not a substitute for the GDP estimate and also is not meant to be a predictor of actual GDP, even though it is possible to use the index to construct a linear combination of another related variable to project GDP. This however, is not the focus of this paper.

\section{Selection of Components for the CIEA}

The selection of components to be used in constructing the CIEA should be guided by the following three key criteria: (i) the selected component should be supported by economic theory to share a common stochastic trend with the standard measure of economic activity (in most cases GDP); (ii) there should be certainty about the availability, frequency, and reliability of the data; ${ }^{3}$ (iii) timeliness of data; and (iv) the data should be procyclical and highly correlated with official GDP estimates. It is also important that the components of the CIEA have broad coverage, covering key sectors of the economy. Ensuring optimal selection of components for the CIEA is critical; which we demonstrate in Section III.

\section{Estimating the CIEA Index}

This paper augments the Conference Board methodology to develop a model to estimate the CIEA for LICs in six distinct steps outlined below.

First, all nominal variables are deflated using the appropriate price deflator to reflect real activities.

Second, monthly changes of the selected components are computed by using the symmetric percentage change formula. ${ }^{4}$ The symmetric percentage change approach allows equal treatment for both negative and positive changes in the series. This would ensure that a percentage increase in a variable $X$ followed by the same percentage decrease would leave the level of $X$ at its original value. However, if $X$ is already in percent change form (e.g., an interest rate), then a simple arithmetic change is computed $\left(x_{t}=X_{t}-X_{t-1}\right)$. The symmetric percentage change is presented below:

\footnotetext{
${ }^{2}$ The selection of countries was purely random and based on availability of high-frequency indicators as well as quarterly GDP series to be used as benchmarks, at the time of writing this paper. The methodology has subsequently been applied to a selected number of LICs, and the algorithm is now available on request.

${ }^{3}$ To address the problem of lags in available data, an autoregressive model is used to estimate the omitted element in each component.

${ }^{4}$ Flow variables need to be cumulated before percent changes can be applied.
} 


$$
x_{t}=200 \frac{\left(X_{t}-X_{t-1}\right)}{\left(X_{t}+X_{t-1}\right)}
$$

Third, the component standardization factor (CF) for each series is computed. This is done by computing the standard deviations $\sigma_{x}$ of each series. The standard deviations are inverted to penalize volatility $\left(w_{x}=1 / \sigma_{x}\right)$. The inverted standard deviations are then summed over $x$ as follows:

$$
k=\sum_{x} w_{x}
$$

Now, the CF is estimated as

$$
r_{x}=(1 / k) \cdot w
$$

Note that the CF $\left(r_{x}\right)$ is inversely related to the standard deviation of monthly changes in each component and is normalized to set the sum of the factors of all components to unity.

Multiplying the monthly changes by the corresponding CF $\left(m_{t}=r_{x}^{*} x_{t}\right)$ gives the adjusted change in each component.

Fourth, the level of the index is computed using the symmetric percent change formula. The first period's index is estimated as $I_{1}=\frac{\left(200+m_{1}\right)}{\left(200-m_{1}\right)}$. This implies the second period's index would be $I_{2}=I_{1} \cdot \frac{\left(200+m_{2}\right)}{\left(200-m_{2}\right)}$, and this is done recursively for all subsequent periods.

The fifth step involves rebasing the index to average 100 for a chosen base year, by multiplying the historical series by 100 and dividing by the average of the periods in the chosen base year.

Finally, the index is seasonally adjusted using the X-12 ARIMA model. ${ }^{5}$

\footnotetext{
${ }^{5}$ This six-step process has been automated on Microsoft Excel and is available upon request.
} 


\section{Application to Selected Countries}

\section{Optimality Test}

We begin our analysis by determining an optimal number of components to be used in estimating the index from a set of available high-frequency data. This process helps to establish which time series best captures dynamics in economic activity. As is common in statistical methodology literature, optimal predictors of a variable or an index can be obtained by analyzing the marginal benefit—-both short and long term — of each additional component in the index. By following this procedure, we estimate the marginal contribution of each component to the overall index.

Using the specific-to-general approach, components' contribution (marginal contribution) to the predictive power of the index is computed. We start with the component that is highly correlated with GDP. This component is used to construct a one-component CIEA and its respective interpolated quarterly GDP estimate. A step-by-step approach is used to add components (in order of highly correlated variables to lowly correlated variables), and in the process estimate the marginal contribution of each new component to the correlation between the existing CIEA-estimated GDP and official GDP, i.e., measuring gains in correlation from additional components. That gain in correlation is the marginal contribution of the new component to the index (Figure 1). We estimate both short- and long-term ${ }^{6}$ marginal contributions of each component. This process is done recursively for all available components, and based on their marginal contributions we are able to determine the number (and types) of components that positively add to the existing correlation with official GDP. This set of components is the optimal number that would ensure both robustness and stability of the index and effectively track the turning points and direction of the economy. ${ }^{7}$

Figure 1 shows estimated marginal contributions of the various components to the predictive power of the index (both short- and long-term contribution). We show that marginal contributions of components differ across countries, requiring country-specific selection of components. Also, component marginal contributions within a given country may differ across timelines. Depending on the planned use of the index — whether to track short- or long-term dynamics - the optimal set of components may differ even within the same country. Finally, for this paper, an optimal set of components for estimating the CIEA was established by selecting components that have positive marginal contributions to the index and are also consistent with the underlying drivers of economic activity in each of the

\footnotetext{
${ }^{6}$ Short- and long-term horizons vary from country to country. The model allows experimentation with the length of time.

${ }^{7}$ Depending on the operational objective of the CIEA indicator being computed, one can choose between components that have maximum (positive and significant) short-term marginal benefits and those that have long-term (positive and significant) marginal benefits.
} 
selected countries. Table 1 shows the selected optimal set of components for each country based on the result of the optimality test presented in Figure 1.

Table 1. Optimal Components

\begin{tabular}{llll}
\hline Botswana & Kenya & Rwanda & Tanzania \\
Broad money & Cement production & Value-added tax (VAT) & Travel reciepts \\
Botswana Stock Exchange (BSE) Index & Car sales & Imports & Manufacturing exports \\
Diamond exports & Electricity consumption & Exports & Capital imports \\
Imports of machinery & Capital imports & Breweries & Value-added tax (VAT) \\
& Credit to private sector & Reserve money & Development spending \\
& & Key manufacturing & M3 \\
& Credit to private sector & \\
\hline
\end{tabular}


Figure 1. Optimality Test
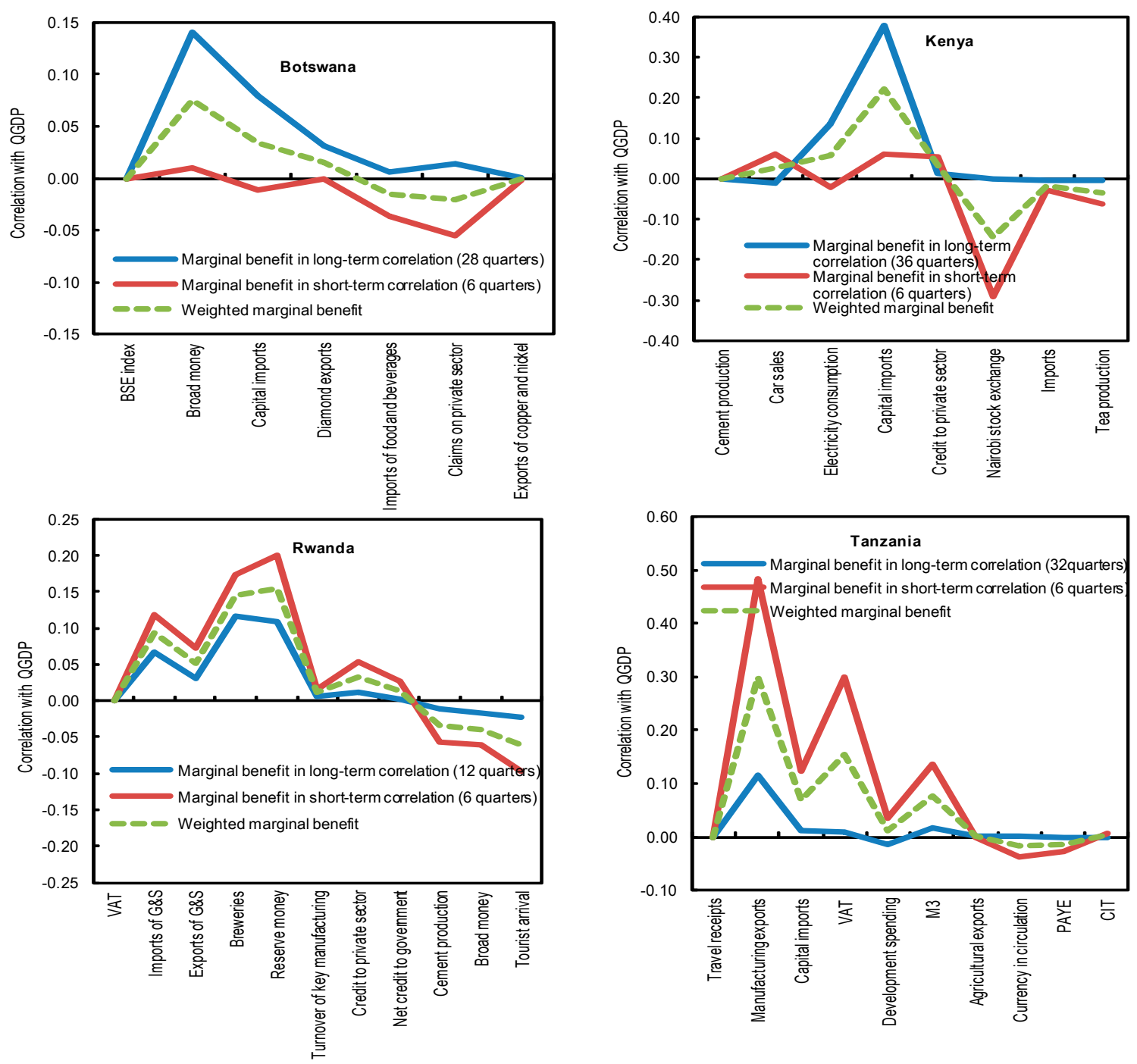


\section{Real CIEA and Annual Changes for Selected Countries}

Figure 2 shows the real CIEA and annual changes for Botswana, Kenya, Rwanda, and Tanzania, using the set of components selected using the optimality test.

Figure 2. Real CIEA

Real CIEA; Index, 2007=100 (right scale) _ Annual change (left scale)
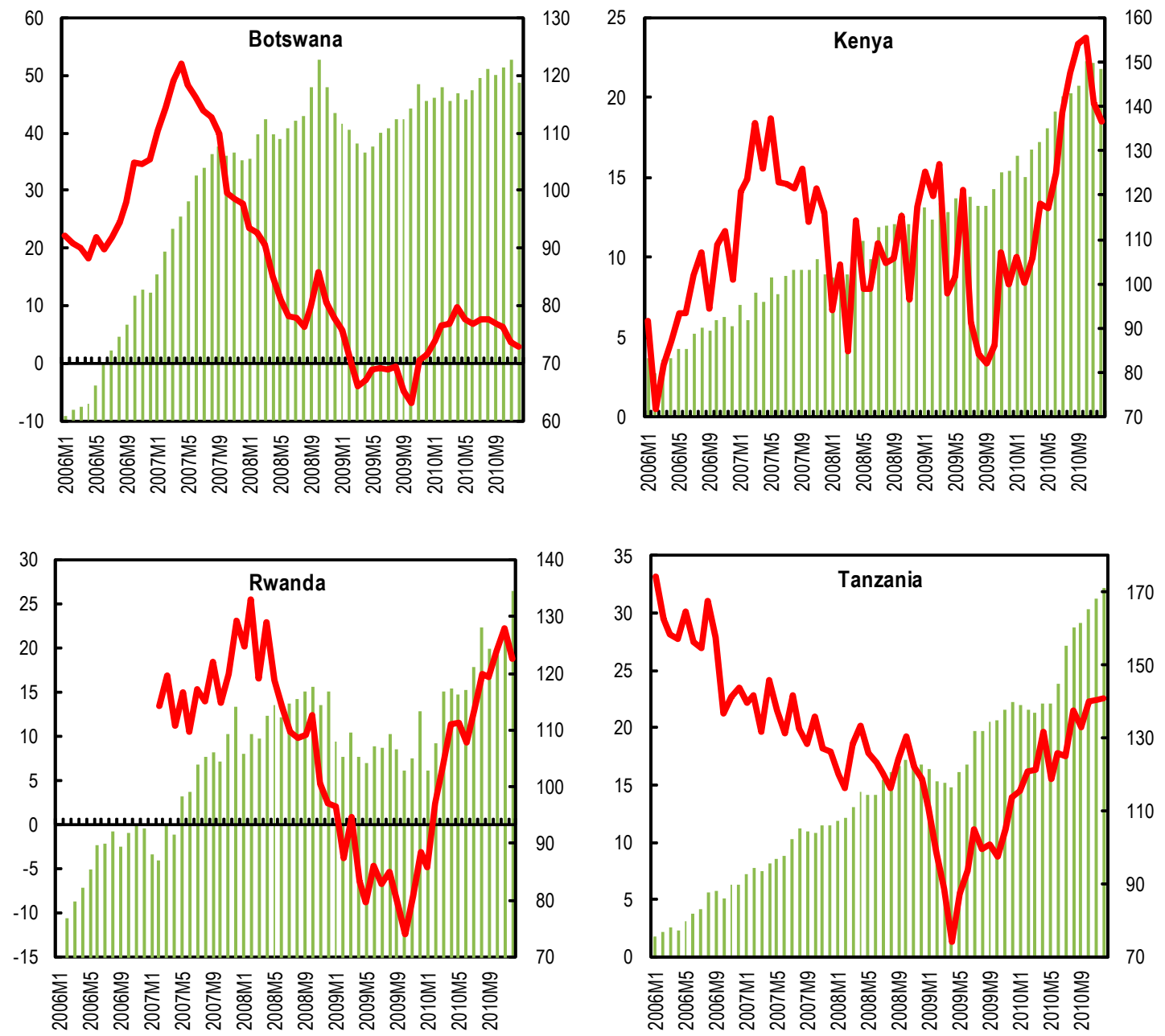

The bars in Figure 2 show the seasonally adjusted real CIEA in each of the selected countries, and the corresponding lines represent year-on-year changes in the real CIEA. The CIEA is computed on monthly basis over varying periods for the different countries, depending on data availability. ${ }^{8}$

\footnotetext{
${ }^{8}$ See appendix I for the component standardization factors (CF) or weights for the various components in CIEA. The weights are rolling weights that change with new information. In some cases, one could fix the weights for a period of time to ensure that enough data with significant information are collected before reestimating the weights.
} 
The CIEA for Botswana closely matches both short- and medium-term dynamics of economic activity between 2004 and 2010. Real GDP growth declined significantly in Botswana in 2008 and 2009 and started to recover in 2010, while inflation rose sharply during this period (from 7.4 percent in January 2007 to 13.7 percent by the end of 2008)mainly because of the global fuel and food crisis in 2008. Although policymakersparticularly monetary authorities - were confronted with the challenge of balancing both the price and output effect of the exogenous shock, the benefit of tracking the short-term dynamics in terms of monthly and/or quarterly movements in economic activity could have resulted in a different monetary policy mix, hence changing the weight put on output and price variability in the loss function minimized by the central bank.

This observation cuts across all the countries in the study. One striking example is Rwanda. While the global crisis exacerbated price pressures - with inflation rising from 5.7 percent in 2007 to about 22 percent in 2008 - at the same time, GDP growth jumped from 6 percent in 2007 to 11.2 percent in 2008 (the highest the country has recorded in the last decade). However, during the same period the central bank continued to pursue a loose monetary policy with the objective of cushioning the impact of the crisis on economic activity. It was obvious that the central bank only became aware of the resilience of output during the period of the crisis, nine months after the end of the year. In hindsight, monetary policy could have been different, with a bigger weight on minimizing inflation variability given the robust output performance in 2008 .

The trends of the CIEA for Kenya and Tanzania in 2007 through 2010 are similar to the dynamics of GDP in these countries. In the four countries in this exercise, the correlation between the annualized CIEA and official annual GDP estimates averages 0.95 , and the CIEA shows a high degree of stability and robustness. This is the same for both the nominal and real CIEA. In addition to being highly correlated, the short-term turning points in the CIEA seem to track closely (see Appendix II for comparisons of turning points) the actual dynamics of economic activities in these countries. This is an important conclusion in the sense that this useful information would help policymakers effectively track the direction of economies in time to make the appropriate policy response.

\section{INTERPolating High-FREQUENCY GDP USING THE CIEA}

To ensure reliability of the CIEA and its close tracking of economic activity, we benchmarked it against official quarterly GDP series. This helps to establish whether the CIEA could be a useful gauge of economic activity.

We used the estimated CIEA as an input in interpolating high-frequency GDP series (in this paper quarterly GDP). This was done by augmenting Friedman's (1962) technique of interpolating a time series variable into a high-frequency variable by using a related series. In this case, the related series is the CIEA—given its strong correlation with official GDP 
estimates. Friedman's methodology so far has been applied to flows. Because the CIEA series are stocks, their selection requires restating the existing approach.

Below is the restatement of Friedman's 1962 methodology, augmented to account for stocks. In the notations below, $\left\{q_{1}^{1}, q_{2}^{1}, \ldots, q_{4}^{n}\right\}$ refer to quarterly estimates of CIEA. ${ }^{9}$

First, the index is converted to a flow variable as follows:

$$
f_{j}^{i}=\frac{q_{j}^{i}}{q_{j-1}^{i}} \text {, when } j \neq 1 \text {, and } f_{1}^{i}=\frac{q_{1}^{i}}{q_{4}^{i-1}} \text { when } j=1 \text {, }
$$

where $i$ and $j$ represent the year and quarter respectively.

Second, the flows are further converted into a series of relatives. These relatives cannot be applied directly because they would yield a sum of quarterly data different from the annual GDP of the respective year. Consequently, the difference between the year-end flows of the CIEA and annual GDP numbers is computed and distributed arithmetically ${ }^{10}$ among the four quarters as follows:

$$
\begin{aligned}
& K_{j}^{i}=\left[\frac{f_{j}^{i}}{f_{j-1}^{i}}-\frac{j}{4}\left(\frac{f_{4}^{i}}{f_{4}^{i-1}}-\frac{G^{i}}{G^{i-1}}\right)\right] G^{i-1}, \text { when } j \neq 1, \text { and } \\
& K_{1}^{i}=\left[\frac{f_{1}^{i}}{f_{4}^{i-1}}-\frac{1}{4}\left(\frac{f_{4}^{i}}{f_{4}^{i-1}}-\frac{G^{i}}{G^{i-1}}\right)\right] G^{i-1}, \text { when } j=1 ; G \text { denotes annual level of GDP. }
\end{aligned}
$$

The interpolated GDP is then normalized as shown in equation(1.7):

$$
Q G D P_{j}^{i}=\frac{K_{j}^{i}}{\sum_{j=1}^{4} K_{j}^{i}}\left(G^{i}\right)
$$

\footnotetext{
${ }^{9}$ This can be done for monthly GDP also.

${ }^{10}$ There is no empirical justification for distributing the difference arithmetically. It can also be distributed geometrically or apply weights to capture seasonal differences.
} 
The strong correlations and close tracking of the turning points (Table 2 and Figure 3 ) between the official quarterly GDP and that derived from the CIEA for all the selected countries is an indication of the usefulness of the CIEA as a tool to gauge the pulse of economic activity in the short term.

Figure 3 shows the interpolated quarterly GDP using the CIEA as a related series. What is striking is the high correlation-both shortand long-run correlations-between the interpolated GDP and the official GDP for the selected countries.
Table 2. Correlation Between Authorites Estimates and CIEA Estimates of Quarterly GDP

\begin{tabular}{lcc}
\hline & $\begin{array}{c}\text { Long-term } \\
\text { Correlation }\end{array}$ & $\begin{array}{c}\text { Short-term } \\
\text { Correlation }\end{array}$ \\
\hline Botswana & 0.79 & 0.78 \\
Kenya & 0.98 & 0.80 \\
Rwanda & 0.94 & 0.72 \\
Tanzania & 0.99 & 0.93 \\
\hline
\end{tabular}

Figure 3. Quarterly GDP Interpolation
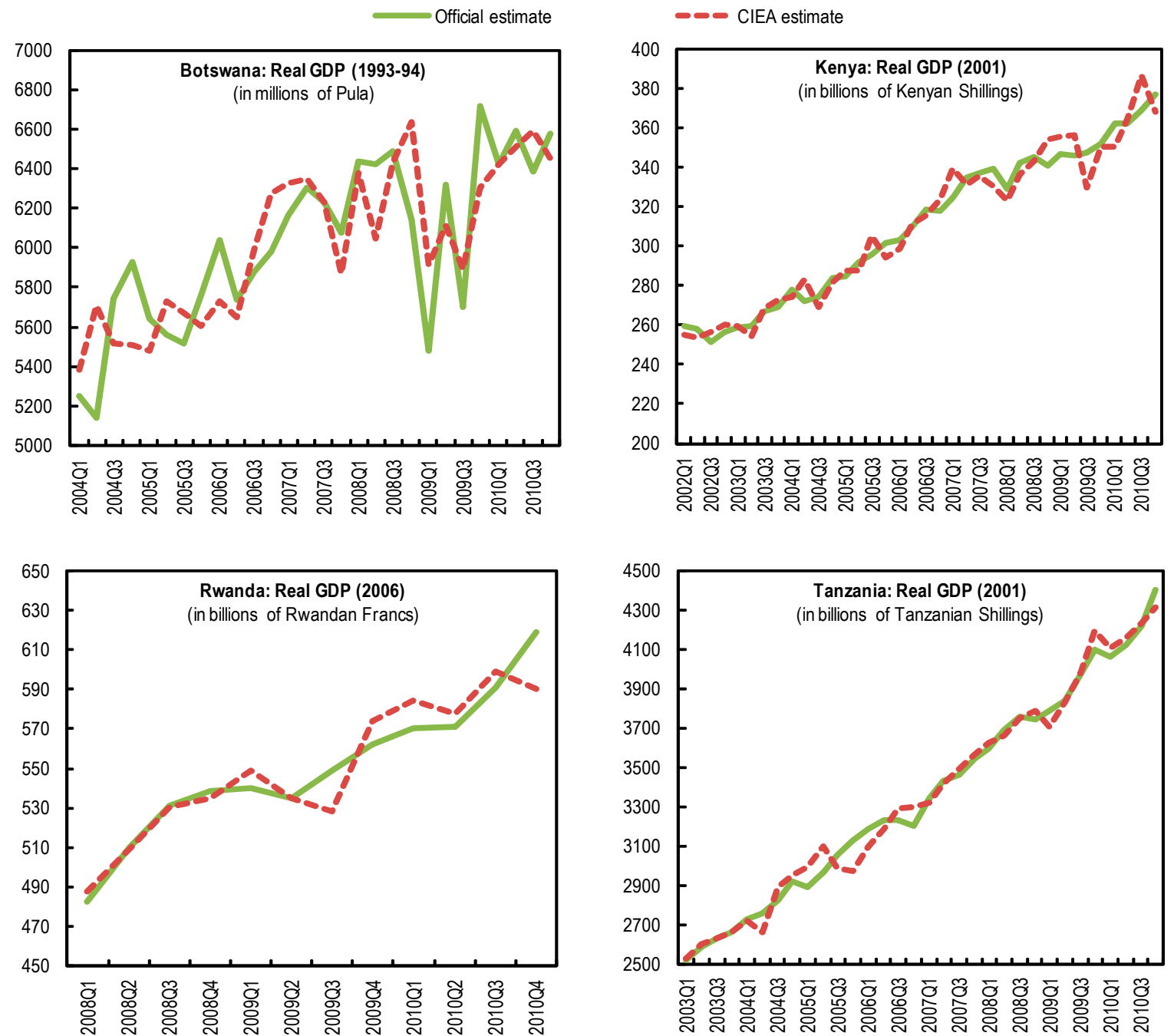


\section{Stability and Robustness Tests}

The robustness of an index (or predictor) can be measured by the degree to which its pairwise correlation with the variable to be predicted (in this case GDP) decreases when another low-correlated component is added to the index. To test for stability of the CIEA, we repeatedly added a low-correlated component to an initial high-correlated component. We then re-estimated the correlation between the CIEA (including the low-correlated variable) and official GDP to measure any loss incurred in correlation as a result of inclusion of the low-correlated variable. This process is done repeatedly for all the components to establish which components add to the predictive power of the CIEA (in this case correlation with GDP) and which component diminishes the predictive power. The results for the selected set of countries are shown in Figure 4.

Figure 4. Sensitivity Analysis

- Low-correlated variable
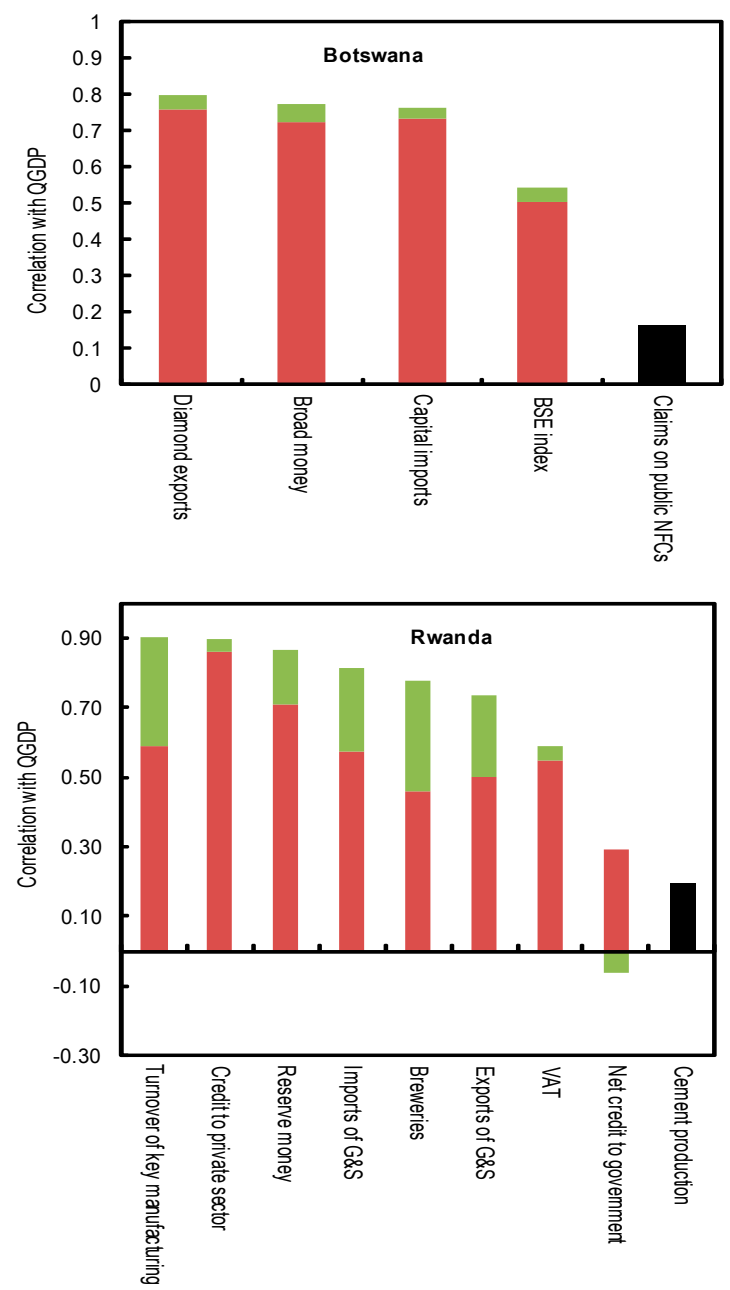

Loss incurred by including low-correlated variable
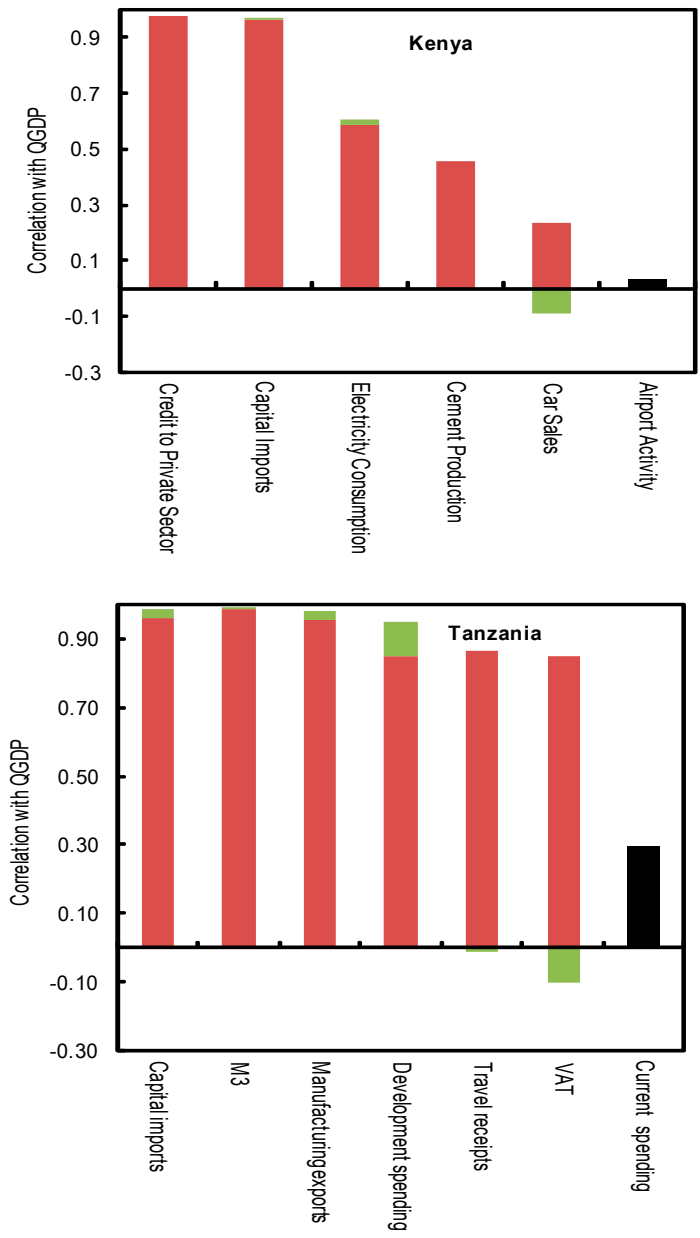
This process is useful in several ways. We are able to estimate the magnitude of loss incurred as a result of adding a low-correlated series, and we can further establish the robustness and stability of individual components - that is, which component is more sensitive to noise. As a demonstration, we try this with only one low-correlated series. For each country, the lowcorrelated component is the last one in the set of components shown in Figure 4. By repeatedly adding the low-correlated series to the other components, we measure the loss of correlation incurred (correlation with GDP). This loss is represented by the top part of the stacked bars. Some key findings are that comparison across countries introduces a bias, depending on how volatile the low-correlated component is. As discussed earlier, the degree of volatility of a component is inversely related to the weight of that component in the index, implying that a highly volatile, low-correlated series will have weak impact on the robustness of the CIEA because of its low weight - "volatility bias." Similarly, a less volatile component with a larger weight will induce a larger loss in predictive power owing to its weight. The volatility bias can be controlled for by standardizing the weights only for the sensitivity analysis.

Among the selected group of countries, we see different results explaining the sensitivity of each component to noise. In Rwanda (Figure 4), the low-correlated component was cement production but was also less volatile, thereby demanding a large share of the index. We observe that the existing components are more sensitive to the inclusion of cement production. We are also able to establish which components of the CIEA in Rwanda are more stable. Credit to the private sector (CPS) and value-added tax (VAT) collections appear to be less sensitive to the inclusion of cement production than the other components. This result would be useful in interpreting the dynamics of the CIEA on account of changes in the various components. For the remaining three countries, low-correlated components happened to be highly volatile (implying low weights) and hence introduced less noise to the predictive power of the CIEA in each country.

\section{Conclusion}

The lack of high-frequency real sector data in most LICs, particularly SSA countries, poses challenges in making macroeconomic policy proactive and flexible enough to anticipate, and where possible provide a timely response to, changes in macroeconomic fundamentals. Although advanced economies and some emerging market economies have extended their tool-kit with useful short-term leading and coincident indicators, this is not the case in most developing economies. This study aims to close this gap by constructing an aggregate and comprehensive measure of overall economic activity that would be available on a timely basis at appropriate frequencies.

Overall, the paper establishes that estimated CIEA is highly correlated and closely tracks official estimates of GDP in all the selected countries. We also show that the CIEA is an important link in closing the gap in high-frequency real sector data currently posing a 
challenge to policymaking in most developing countries as countries move to more flexible monetary management that requires responding to short-term changes in aggregate demand.

While we acknowledge that the CIEA is not a replacement for the standard measures of economic activity (i.e., GDP), it is particularly helpful in gauging short-term dynamics of economic activity; serving as an early signal on the direction of the economy; and acting as a tool to anticipate the future direction of output to support policymaking in the absence of timely and high-frequency GDP data. 
Appendix I

Component Standarization Factors

\begin{tabular}{|c|c|c|}
\hline Indicator & $\begin{array}{l}\text { Weight on } \\
\text { Real Index }\end{array}$ & $\begin{array}{l}\text { Weight on } \\
\text { Nominal Index }\end{array}$ \\
\hline \multicolumn{3}{|l|}{ Botswana } \\
\hline Broad money & 27.90 & 18.59 \\
\hline BSE Index & 20.86 & 13.69 \\
\hline Diamond exports & 25.05 & 32.29 \\
\hline Imports of machinery & 26.20 & 35.44 \\
\hline \multicolumn{3}{|l|}{ Kenya } \\
\hline Cement production & 13.86 & 13.23 \\
\hline Car sales & 5.27 & 5.04 \\
\hline Electricity consumption & 18.63 & 17.79 \\
\hline Capital imports & 11.35 & 11.14 \\
\hline Credit to private Sector & 50.86 & 52.80 \\
\hline \multicolumn{3}{|l|}{ Rwanda } \\
\hline VAT & 10.46 & 10.25 \\
\hline Imports & 6.03 & 5.90 \\
\hline Exports & 3.74 & 3.66 \\
\hline Breweries & 6.02 & 5.92 \\
\hline Reserve money & 21.68 & 22.67 \\
\hline Key manufacturing & 8.30 & 8.20 \\
\hline CPS & 39.75 & 39.40 \\
\hline NCG & 4.02 & 3.99 \\
\hline \multicolumn{3}{|l|}{ Tanzania } \\
\hline Travel reciepts & 7.19 & 7.01 \\
\hline Manufacturing exports & 11.77 & 11.92 \\
\hline Capital imports & 11.45 & 11.61 \\
\hline VAT & 9.53 & 9.27 \\
\hline Development spending & 6.43 & 6.28 \\
\hline M3 & 53.63 & 53.90 \\
\hline
\end{tabular}




\section{Appendix II}

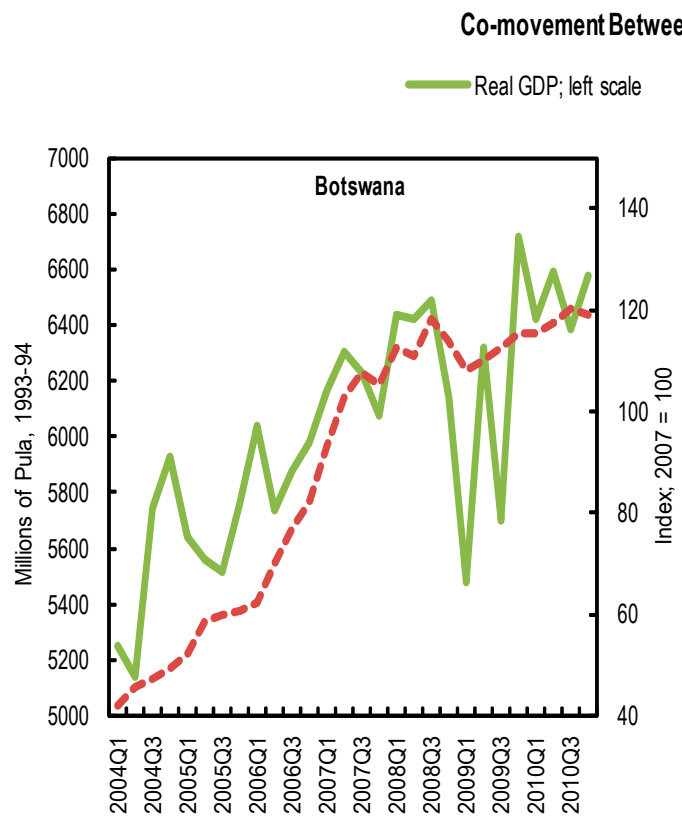

- Real CIEA; right scale
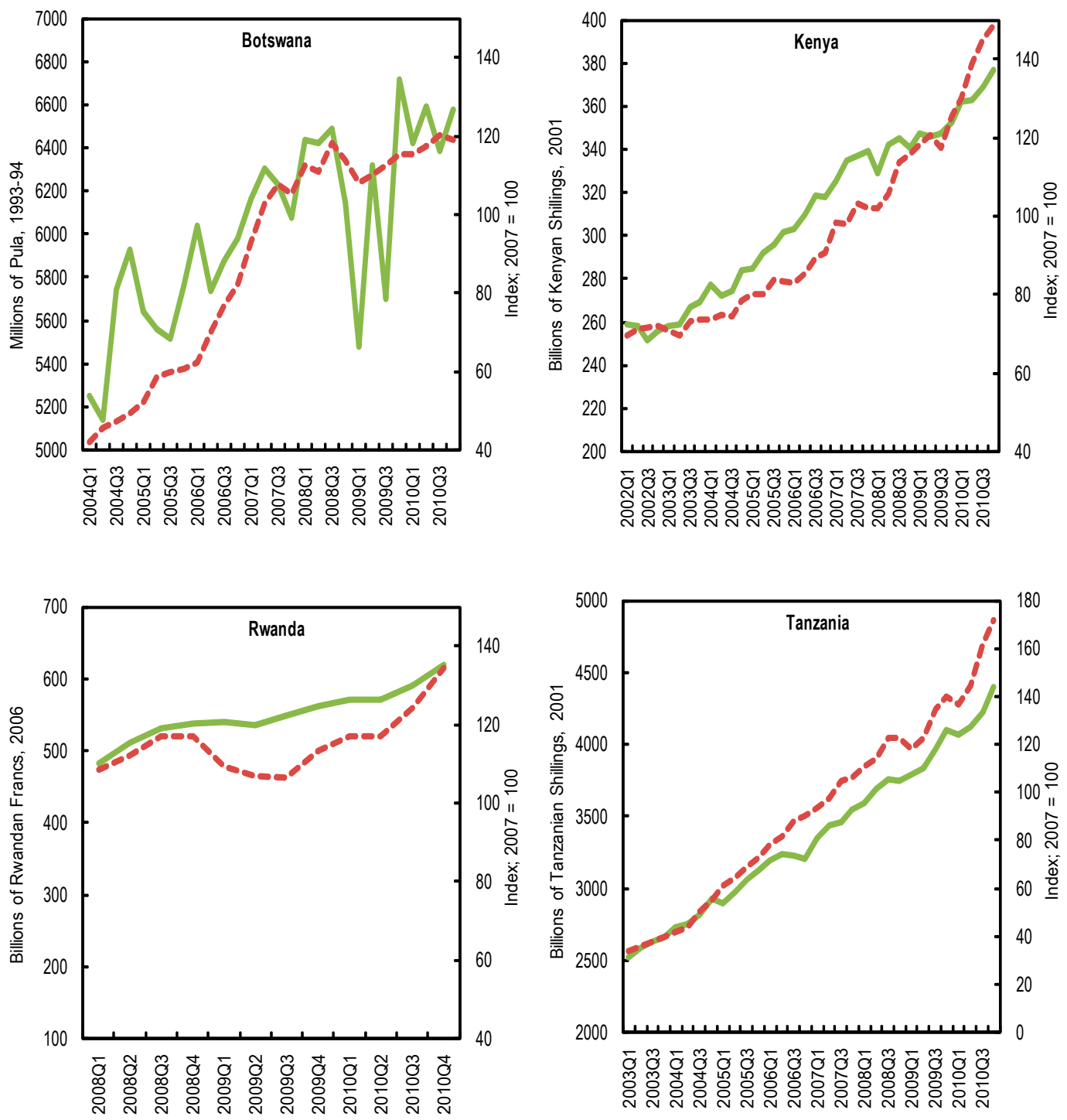

${ }^{1}$ Trend analysis conducted using HP Filter. 


\section{References}

Albu, Lucian-Liviu, 2008, “A Model to Estimate the Composite Index of Economic Activity in Romania,” IEF-RO, Romanian Journal of Economic Forecasting.

Fabiano, S, A. Locarno, G. Oneto, and P. Sestito, September 2000, "The Sources of Unemployment Fluctuations: An Empirical Application to the Italian Case," ECB Working Paper No. 29.

Friedman Milton, 1962, "Interpolation of a Time Series by Related Series," Journal of the American Statistical Association, Vol. 57, No. 3000 (December), pp. 729-757.

Lamy, R., and P. Sabourin, 2001, "Monitoring Regional Economies in Canada with New High-Frequency Coincident Indexes," Working Paper 2001-05, Department of Finance, Government of Canada.

Layton, A., and G.H. Moore, 1989, "Leading Indicators for the Service Sector," Journal of Business and Economic Statistics, 7 (3), pp. 379-386.

Mitchell, W., and A.F. Burns, 1938, "Statistical Indicators of Cyclical Revivals and Recessions," Bulletin, 69, National Bureau of Economic Research, reprinted in G.H. Moore (1961), ed., Business Cycle Indicators: Contributions to the Analysis of Current Business Conditions, Vol. I, National Bureau of Economic Research.

Moore, G. H., 1950 "Statistical Indicators of Cyclical Revivals and Recessions," Occasional Paper 31 (New York: National Bureau of Economic Research).

Moore, G. H., 1983 "Business Cycles: Business Cycles, Inflation, and Forecasting in Studies in Business Cycles," National Bureau of Economic Research, Volume 24, (Chicago: University of Chicago Press).

Moore, G.H., and, J. Shiskin, 1967, "Indicators of Business Expansions and Contractions". (New York: National Bureau of Economic Research.)

Stock, J. H., and M. W. Watson, 1989, "New Indexes of Coincident and Leading Economic Indicators," NBER Macroeconomics Annual (Cambridge, Mass.: MIT Press).

Zarnowitz, V., 1996, Business Cycles: Theory, History, Indicators and Forecasting, in Studies in Business Cycles, NBER, Volume 27 (Chicago: The University of Chicago Press). 